\title{
Combined Neutrophil-to-Lymphocyte Ratio and CURB-65 Score as an Accurate Predictor of Mortality for Community-Acquired Pneumonia in the Elderly
}

This article was published in the following Dove Press journal:

International Journal of General Medicine

\section{Ding-Yun Feng $\mathbb{D}^{*}$ \\ Xiao-Ling Zou (iD* \\ Yu-Qi Zhou* \\ Wen-Bin Wu (DD \\ Hai-Ling Yang \\ Tian-Tuo Zhang $\mathbb{D}$}

Department of Pulmonary and Critical Care Medicine, The Third Affiliated Hospital of Sun Yat-Sen University, Institute of Respiratory Diseases of Sun Yat-Sen University, Guangzhou, People's Republic of China

*These authors contributed equally to this work
Correspondence: Tian-Tuo Zhang Department of Pulmonary and Critical Care Medicine, Third Affiliated Hospital of Sun Yat-Sen University, Institute of Respiratory Diseases of Sun Yat-Sen University, 600 Tianhe Road, Guangzhou, 5 I0630, People's Republic of China

Tel +86-20-8525224l

Email zhtituli@I63.com
Purpose: Community-acquired pneumonia (CAP) is common among the elderly; it typically has a poor prognosis and high mortality. This study evaluated the factors predicting CAPrelated in-hospital mortality in the elderly to identify a simpler and more accurate predictor. Patients and Methods: This was a single-center, retrospective study. The data used in this study was collected from all older patients ( $\geq 65$ ) with CAP admitted to our hospital between January 2012 and April 2020.

Results: A total of 2028 older patients with CAP were included; 121 (5.97\%) died in hospital. Of the patients in the study, 1267 (62.5\%) were men and $261(12.9 \%)$ had a history of malignant tumors. After performing univariate and multivariate Cox regression analyses, sex, history of malignant tumor, CURB-65 score, neutrophil-to-lymphocyte ratio (NLR), hemoglobin level, and NLR*CURB-65 levels were associated with CAP mortality. By comparing the area under the receiver operating characteristic (ROC) curves of the predicted factors, the NLR*CURB-65 level used to predict CAP mortality in the elderly was 0.755 , and was superior to other measurements. All included patients were then dichotomized into two groups based on NLR*CURB-65 level $(\leq 9.06$ and $>9.06$ ) according to the ROC analysis. Patients with a high NLR*CURB-65 level had higher inhospital mortality than those with a low NLR*CURB-65 level. The two divided groups showed significant differences in age, sex, smoking history, comorbidity, and laboratory findings. This indicates that NLR*CURB-65 is a predictive index that could reflect the comprehensive condition of older patients with CAP.

Conclusion: NLR*CURB-65 is a simpler and more accurate predictor of CAP-related inhospital mortality in the elderly.

Keywords: NLR*CURB-65, community-acquired pneumonia, mortality, predictor

\section{Introduction}

Despite rapid advances in medical technology and significant improvements in global health, community-acquired pneumonia (CAP) remains a major clinical and public health problem globally. ${ }^{1}$ The Global Burden of Diseases, Injuries, and Risk Factors Study in 2017 estimated that lower respiratory tract infections affected 471.8 million people, and caused 2.6 million deaths in 2017 alone. ${ }^{2}$ Since 1950, the advent of antibiotics has been regarded as a crucial turning point in the treatment of pneumonia; however, though new antibiotics have been found to combat infection, the reduction in the pneumonia-related death rate has been relatively limited. ${ }^{1}$ The proportion of older patients is increasing due to 
a globally aging population; in hospitalized older patients, the rate of pneumonia treatment is higher than that for other respiratory diseases. ${ }^{3,4}$ The mortality rate is also higher in older adults than in young people. ${ }^{4}$ Although several studies have examined prognostic factors of CAP such as serum procalcitonin, C-reactive protein, and comorbidity in older patients, ${ }^{5-7}$ various findings were obtained from different approaches and had differing specificity and sensitivity. This study aimed to evaluate the factors that predict CAP-related inhospital mortality in the elderly and identify simpler and more accurate predictors through comparison of the classical predictors.

\section{Patients and Methods}

This was a single-center retrospective study. Data was obtained related to all incidences of CAP that occurred in the Third Affiliated Hospital of Sun Yat-sen University, Guangdong, China, between January 2012 and April 2020. Variables of interest included age, sex, comorbidity, and in-hospital mortality. All study patients were 65 years of age or older ( $\geq 65$ years). The criteria for diagnosing $\mathrm{CAP}^{8}$ included the presence of a new pulmonary infiltrate associated with at least one of the following: new or increased cough with or without purulent tracheobronchial secretion or new pathogenic bacteria isolated from sputum or tracheal aspirate culture with $\geq 10^{4}$ colonyforming units $/ \mathrm{mL}$, fever $\left(>37.8^{\circ} \mathrm{C}\right)$ or hypothermia $\left(<35.6^{\circ} \mathrm{C}\right)$, leukocytosis, left shift, or leukopenia based on local normal values. Patients with acquired immunodeficiency syndrome, interstitial lung disease, or those missing key data were excluded. Patients with malignant tumors with an Eastern Cooperative Oncology Group (ECOG) score $\geq 4$ were also excluded.

Disease severity was evaluated using the validated CURB-65 scoring system, ${ }^{9}$ which included confusion, urea $>7 \mathrm{mmol} / \mathrm{L}$, respiratory rate $\geq 30$ breaths $/ \mathrm{min}$, blood pressure $\leq 90 / 60 \mathrm{mmHg}$, and age $\geq 65$ years.

\section{Statistical Analysis}

The in-hospital survival of older patients with CAP was the main endpoint of this study. Survival was defined as the period between CAP diagnosis until death or last follow-up. A multivariate analysis using a stepwise Cox proportional hazards model was used to examine the independent significance of baseline characteristics and explanatory variables. The performance of relevant parameters was assessed using the Kaplan-Meier method, and differences in survival between groups were compared using the Log rank test. In addition, the receiver operating characteristic (ROC) curves of relevant parameters for predicting CAP-related in-hospital mortality were plotted. A sensitivity score less than the cutoff point indicated in-hospital mortality, while a score greater than the cutoff point indicated survival after discharge; both could be evaluated for each possible cutoff point. The cutoff point representing the highest Youden index (sensitivity+specificity $-1)$ was selected as the optimal threshold value. Hazard ratios (HRs) and 95\% confidence intervals (CIs) were calculated to measure the effects of relevant parameters on prognosis; a HR greater than 1 indicated a worse prognosis in patients with a relevant parameter, while a HR less than 1 indicated a better prognosis. The significance level was set at $\alpha=0.05$, and all p-values were based on two-sided tests. All statistical analyses were performed using IBM SPSS Statistics version 20 (IBM Corp., Armonk, NY, USA).

This study was approved by the institutional review board of the hospital and the ethics committee of the Third Affiliated Hospital of Sun Yat-sen University ([2019] 02-238-01). This study was conducted and designed in accordance with the Declaration of Helsinki. The need for written informed consent was waived because of the non-interventional design. Patient information was kept confidential.

\section{Results}

During the study period, 5916 inpatients developed CAP, 2028 of which were older adults who were included in the study; of these, 121 died (Figure 1). A total of 1267 patients $(62.5 \%)$ were men. Diabetes mellitus was the most common comorbidity, followed by malignant tumors. The mean CURB-65 score was 1.39 \pm 0.61 (Table 1).

To identify the independent factors that affected CAPrelated in-hospital mortality in the elderly, a Cox regression analysis was performed. Univariate Cox regression

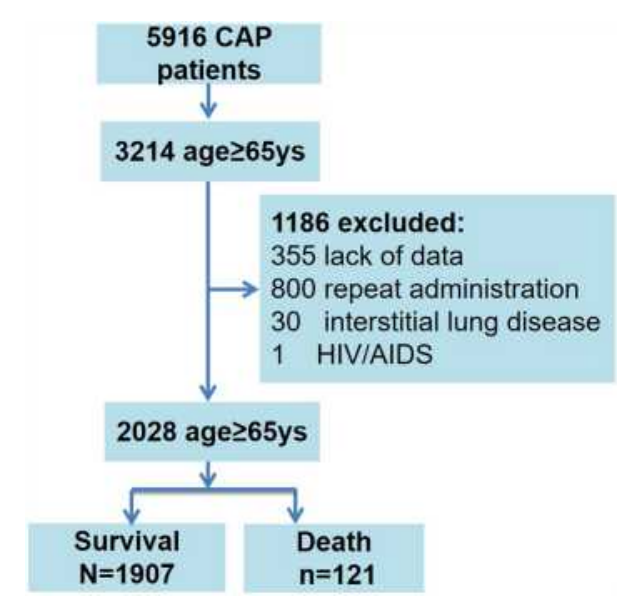

Figure I Analysis roadmap. 
Table I Demographic, Laboratory and Clinical Variables of CAP in the Elderly

\begin{tabular}{|c|c|}
\hline Characteristics & Value \\
\hline Age, $y$, mean $\pm S D$ & $76.93 \pm 7.53$ \\
\hline Gender, male & $1267(62.5 \%)$ \\
\hline Smoke & $720(35.5 \%)$ \\
\hline \multicolumn{2}{|l|}{ Comorbidity } \\
\hline Diabetes mellitus & $486(24.0 \%)$ \\
\hline COPD & $|7|(8.4 \%)$ \\
\hline Asthma & $55(2.7 \%)$ \\
\hline Bloodstream infection & $9(0.4 \%)$ \\
\hline Malignant tumor & $26 I(12.9 \%)$ \\
\hline Acute heart failure & $54(2.7 \%)$ \\
\hline CURB-65 score & $1.39 \pm 0.61$ \\
\hline WBC, $* 10 e 9 / 1$, mean $\pm S D$ & $8.58 \pm 4.74$ \\
\hline $\mathrm{NLR}$, mean $\pm \mathrm{SD}$ & $6.50 \pm 8.13$ \\
\hline $\mathrm{HGB}, \mathrm{g} / \mathrm{l}$, mean $\pm \mathrm{SD}$ & $117.67 \pm 19.78$ \\
\hline $\mathrm{BUN}, \mathrm{mmol} / \mathrm{l}, \mathrm{mean} \pm \mathrm{SD}$ & $6.37 \pm 3.89$ \\
\hline $\mathrm{ALT}, \mathrm{U} / \mathrm{L}$, mean $\pm \mathrm{SD}$ & $29.54 \pm 51.19$ \\
\hline $\mathrm{AST}, \mathrm{U} / \mathrm{L}$, mean $\pm \mathrm{SD}$ & $33.63 \pm 53.10$ \\
\hline NLR*CURB-65 & $10.56 \pm 19.02$ \\
\hline Mortality & $|2|(5.97 \%)$ \\
\hline
\end{tabular}

Abbreviations: CAP, community-acquired pneumonia; COPD, chronic obstructive pulmonary disease; WBC, white blood cell; NLR, neutrophil-to-lymphocyte ratio; HGB, hemoglobin; BUN, blood urea nitrogen; ALT, alanine transaminase; AST, aspartate aminotransferase.

analysis identified the following independent factors that affect in-hospital mortality: age, sex, history of malignant tumors, acute heart failure, CURB-65 score, white blood cell count, neutrophil-to-lymphocyte ratio (NLR), hemoglobin (HGB) level, blood urea nitrogen, alanine transaminase, aspartate aminotransferase, and NLR*CURB-65 levels. The results of the multivariate analysis showed that sex, history of malignant tumors, CURB-65 score, NLR, HGB level, and NLR*CURB-65 level were associated with CAP-related mortality in the elderly (Table 2). To analyze the predictive value of the aforementioned significant parameters, a ROC analysis was conducted. It was found that the NLR*CURB-65 level was the most significant predictor of in-hospital survival (Table 3). The area under the ROC curve of the NLR*CURB-65 level predicting CAP-related in-hospital mortality in the elderly was 0.755 ( $\mathrm{P}<0.001,95 \% \mathrm{CI}, 0.711-0.798$; Figure 2).

The cutoff point was identified as 9.06 , having the highest predictive performance for both specificity and sensitivity. A high NLR*CURB-65 level was significantly associated with worse survival $(\mathrm{P}<0.001)$ (Figure 3 ).

Patients with high and low NLR*CURB-65 levels were compared to analyze differences between the two groups. The two patient groups stratified by NLR*CURB-65 level showed significant differences in age, sex, smoking history, comorbidity, and laboratory test data (Table 4). This indicates that a predictive index using NLR*CURB-65 could reflect the comprehensive condition of older patients with CAP.

\section{Discussion}

CAP is commonly seen in the elderly ${ }^{10,11}$ and often results in poor prognosis and high mortality. ${ }^{12}$ In this study, it was found that the in-hospital mortality rate in this population was $5.87 \%$, which was consistent with previous studies ${ }^{12-14}$ This high mortality rate indicates that particular attention should be paid to older patients with CAP. To further understand the clinical characteristics of CAP and determine more accurate prognostic factors, the demographic characteristics and comorbidities of CAP in the elderly were analyzed. Along with the results of the regression analysis, it was found that sex affected the prognosis of CAP in the elderly, with male patients having a higher mortality rate. This result is consistent with that of previous studies, ${ }^{15,16}$ and may be due to the fact that older male patients with pneumonia often develop cardiovascular diseases. ${ }^{16}$ It may also be related to the presence of a higher number of risk factors such as smoking, alcoholism, and occupational exposure to toxic substances in this demographic. ${ }^{17,18}$ In the current study, patients who died due to a malignant tumor were excluded, but a history of malignant tumors was associated with CAP-related mortality in the elderly. This may be related to the low immune function of patients with tumors and their decreased ability to resist infection.

CURB-65 is a classic tool for evaluating CAP severity, and is comprised of confusion, urea $>7 \mathrm{mmol} / \mathrm{L}$, respiratory rate $\geq 30 / \mathrm{min}$, blood pressure $\leq 90 / 60 \mathrm{mmHg}$, and age $\geq 65$ years. $^{9}$ To determine if, in patients aged over 65 years, CURB- 65 was still associated with CAP prognosis, the relationship between CURB-65 and CAP prognosis was analyzed; it was found that a correlation exists, which is consistent with the results of previous studies. ${ }^{19}$ HGB level was also analyzed in this study and was considered a predictor of CAP prognosis in the elderly, 
Table 2 Univariate and Multivariate Cox Regression Analyses of Prognostic Factors for CAP-Related In-Hospital Mortality in the Elderly

\begin{tabular}{|c|c|c|c|c|c|c|c|c|}
\hline \multirow[t]{2}{*}{ Characteristics } & \multirow{2}{*}{$\begin{array}{c}\text { Related Mortality } \\
n=|2|(5.97 \%)\end{array}$} & \multirow{2}{*}{$\begin{array}{c}\text { Survival } \\
n=\mid 907(94.03 \%)\end{array}$} & \multicolumn{3}{|c|}{ Univariate } & \multicolumn{3}{|c|}{ Multivariate } \\
\hline & & & HR & $95 \% \mathrm{Cl}$ & $\mathbf{P}$ & HR & $95 \% \mathrm{Cl}$ & $\mathbf{P}$ \\
\hline Age, $y$, mean $\pm S D$ & $78.27 \pm 8.5 I$ & $76.85 \pm 7.46$ & 1.028 & $1.004-1.052$ & 0.021 & 1.012 & $0.987-1.038$ & 0.359 \\
\hline Gender, male & $88(72.7 \%)$ & $1179(61.8 \%)$ & 1.675 & $1.123-2.499$ & 0.012 & 1.604 & $1.053-2.443$ & 0.028 \\
\hline Smoke & $45(37.2 \%)$ & $675(35.4 \%)$ & 1.127 & $0.78-1.63$ & 0.524 & & & \\
\hline \multicolumn{9}{|l|}{ Comorbidity } \\
\hline Diabetes mellitus & $26(21.5 \%)$ & $460(24.1 \%)$ & 0.845 & $0.548-1.304$ & 0.447 & & & \\
\hline COPD & $15(12.4 \%)$ & $156(8.2 \%)$ & 1.494 & $0.87-2.566$ & 0.145 & & & \\
\hline Asthma & $3(2.5 \%)$ & $52(2.7 \%)$ & 0.92 & $0.292-2.893$ & 0.886 & & & \\
\hline Bloodstream infection & 0 & $9(0.5 \%)$ & 0.049 & $0-4642.4$ & 0.607 & & & \\
\hline Malignant tumor & $39(32.2 \%)$ & $222(11.6 \%)$ & 3.222 & $2.20 I-4.718$ & $<0.001$ & 2.921 & $1.958-4.358$ & $<0.001$ \\
\hline Acute heart failure & $9(7.4 \%)$ & $45(2.4 \%)$ & 2.869 & $1.455-5.658$ & 0.002 & 1.598 & $0.74-3.451$ & 0.233 \\
\hline CURB-65 score, mean \pm SD & $1.91 \pm 0.95$ & $1.37 \pm 0.57$ & 2.521 & $2.103-3.023$ & $<0.001$ & 2.763 & $1.98-3.855$ & $<0.001$ \\
\hline WBC,*I0e9/l, mean $\pm S D$ & $10.58 \pm 6.27$ & $8.45 \pm 4.60$ & 1.053 & $1.031-1.076$ & $<0.001$ & 1.023 & $0.993-1.053$ & 0.133 \\
\hline NLR, mean $\pm S D$ & $|3.54 \pm| 6.7 \mid$ & $6.01 \pm 7.03$ & 1.041 & $1.033-1.049$ & $<0.001$ & 1.052 & $1.029-1.075$ & $<0.001$ \\
\hline HGB, g/l, mean $\pm S D$ & $109.00 \pm 29.50$ & $118.22 \pm 19.32$ & 0.977 & $0.969-0.986$ & $<0.001$ & 0.987 & $0.978-0.996$ & 0.004 \\
\hline BUN, mmol/l, mean $\pm S D$ & $8.21 \pm 5.45$ & $6.25 \pm 3.75$ & 1.083 & $1.054-1.114$ & $<0.001$ & 0.963 & $0.919-1.008$ & 0.109 \\
\hline $\mathrm{ALT}, \mathrm{U} / \mathrm{L}, \mathrm{mean} \pm \mathrm{SD}$ & $43.63 \pm 104.75$ & $28.64 \pm 48.66$ & 1.002 & $1.001-1.004$ & 0.005 & 1.002 & $0.998-1.006$ & 0.254 \\
\hline $\mathrm{AST}, \mathrm{U} / \mathrm{L}$, mean $\pm \mathrm{SD}$ & $43.95 \pm 68.07$ & $32.58 \pm 51.96$ & 1.001 & $1.000-1.003$ & 0.047 & I & $0.995-1.004$ & 0.894 \\
\hline NLR*CURB-65 & $29.21 \pm 46.11$ & $9.38 \pm 15.10$ & 1.013 & $1.011-1.016$ & $<0.001$ & 0.987 & $0.976-0.998$ & 0.021 \\
\hline
\end{tabular}

Abbreviations: CAP, community-acquired pneumonia; COPD, chronic obstructive pulmonary disease; WBC, white blood cell; NLR, neutrophil-to-lymphocyte ratio; HGB, hemoglobin; BUN, blood urea nitrogen; ALT, alanine transaminase; AST, aspartate aminotransferase.

a finding which has also been previously reported. ${ }^{20-22}$ This may be due to the effects of inflammatory cytokines, inadequate red cell production, and excessive red cell destruction in patients with $\mathrm{CAP}^{22,23} \mathrm{NLR}$ is a simple laboratory biomarker

Table 3 The Area Under of the ROC Curves in the Factors Predicting CAP-Related In-Hospital Mortality in the Elderly

\begin{tabular}{|l|l|l|l|}
\hline Characteristics & AUC & \multicolumn{1}{|c|}{$\mathbf{P}$} & \multicolumn{1}{|c|}{$\mathbf{9 5} \% \mathbf{C I}$} \\
\hline NLR*CURB-65 & 0.755 & $<0.001$ & $0.71 \mathrm{I}-0.798$ \\
NLR, mean \pm SD & 0.720 & $<0.00 \mathrm{I}$ & $0.675-0.766$ \\
CURB-65 score & 0.678 & $<0.00 \mathrm{I}$ & $0.625-0.732$ \\
Malignant tumor & 0.603 & $<0.00 \mathrm{I}$ & $0.546-0.66$ \\
Gender, male & 0.555 & 0.044 & $0.504-0.605$ \\
HGB, g/l, mean \pm SD & 0.367 & $<0.00 \mathrm{I}$ & $0.308-0.425$ \\
\hline
\end{tabular}

Abbreviations: CAP, community-acquired pneumonia; NLR, neutrophil-tolymphocyte ratio; HGB, hemoglobin. and a promising candidate predictor of mortality in patients with CAP. ${ }^{24-26}$ In the current study, NLR was also found to be related to CAP prognosis in the elderly; NLR was associated with systemic inflammation and the severity of CAP. As the above factors are commonly used for predicting CAP prognosis in the general patient population and in the elderly, this study recommends the measurement of NLR*CURB-65 level to serve as a simpler and more accurate predictor. In fact, the NLR*CURB-65 was a significant predictor of CAP mortality in the elderly. Furthermore, the ROC curve of NLR*CURB-65 was an excellent predictor with a perfect AUC. To further analyze the NLR*CURB-65 value, all included patients were dichotomized into two groups based on the NLR*CURB-65 level ( $\leq 9.06$ and $>9.06$ ) according to the ROC analysis. Patients with a high NLR*CURB-65 level had higher inhospital mortality than those with a low NLR*CURB-65 


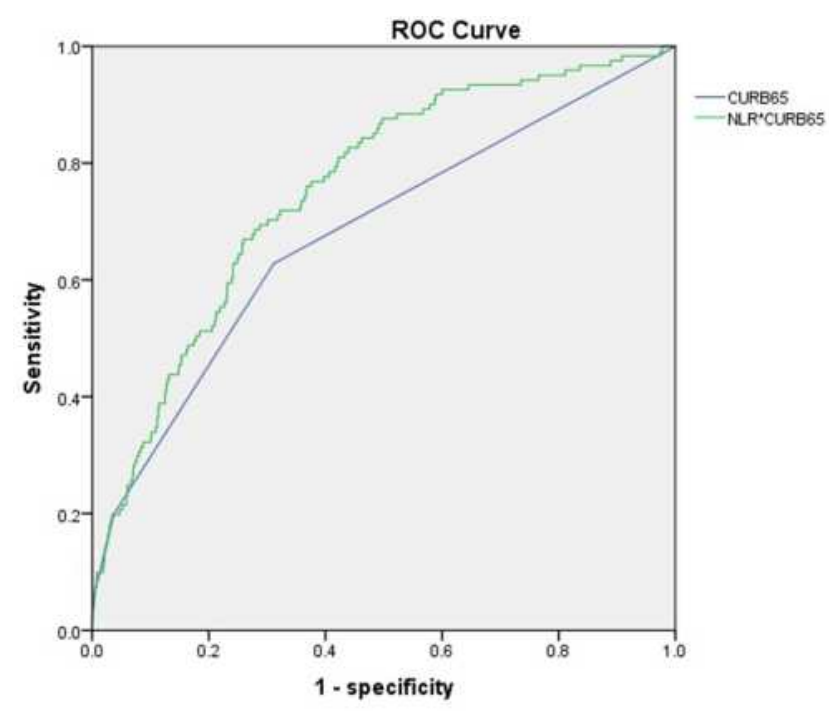

Figure 2 Area under the ROC curves of the NLR*CURB-65 level and CURB-65 predicting CAP-related in-hospital mortality in the elderly.

Abbreviations: ROC, receiver operating characteristic; NLR, neutrophillymphocyte ratio.

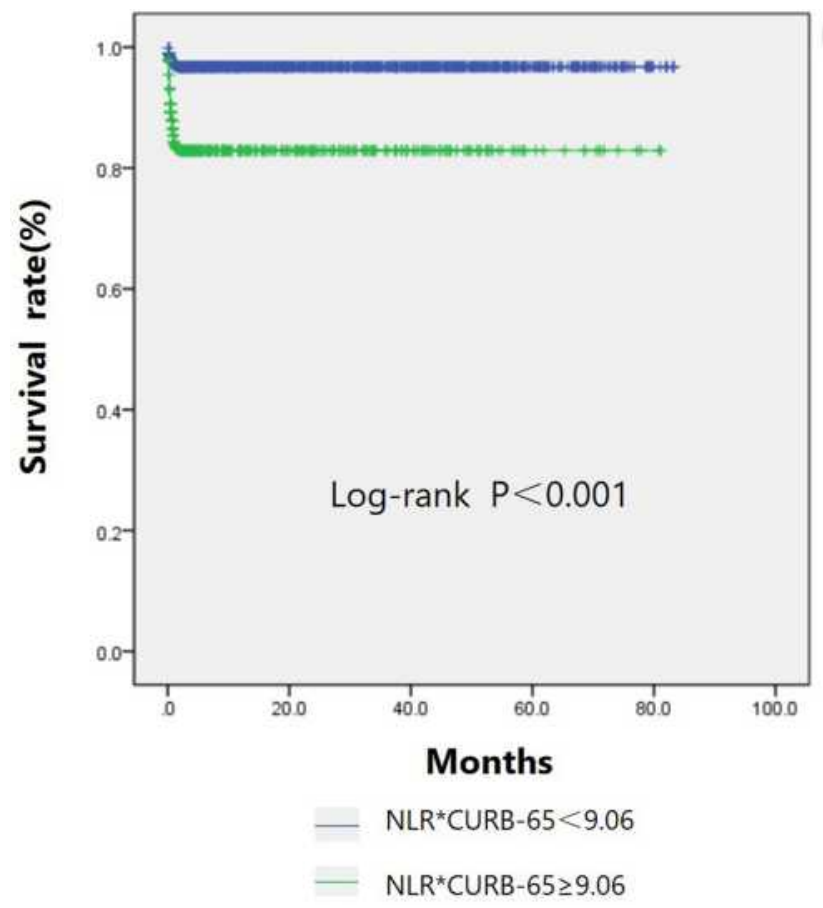

Figure 3 Kaplan-Meier survival curves of the overall survival of older patients with CAP with different NLR*CURB-65 levels.

Abbreviations: CAP, community-acquired pneumonia; NLR, neutrophil-lymphocyte ratio.

level. The groups also showed significant differences in age, sex, smoking history, comorbidities, and laboratory data. This finding indicated that the NLR*CURB-65 level was a predictive index that could reflect the comprehensive condition of older patients with CAP.
Table 4 Baseline Demographic and Clinical Characteristics of CAP in the Elderly Patients with Different Level of NLR*CURB-65

\begin{tabular}{|c|c|c|c|}
\hline \multirow[t]{2}{*}{ Characteristics } & $\begin{array}{c}\text { High } \\
\text { NLR*CURB-65 }\end{array}$ & $\begin{array}{c}\text { Low } \\
\text { NLR*CURB-65 }\end{array}$ & \multirow[t]{2}{*}{$P$ value } \\
\hline & $n=576(28.4 \%)$ & $n=\mid 452(7 \mid .6 \%)$ & \\
\hline Age, $y$, mean $\pm S D$ & $78.13 \pm 7.56$ & $76.45 \pm 7.47$ & $<0.001$ \\
\hline Gender, male & $417(72.9 \%)$ & $850(59.5 \%)$ & $<0.001$ \\
\hline Smoke & $243(42.5 \%)$ & $477(33.4 \%)$ & $<0.001$ \\
\hline \multicolumn{4}{|l|}{ Comorbidity } \\
\hline Diabetes mellitus & $155(27.1 \%)$ & $33 \mid(23.1 \%)$ & 0.05 \\
\hline COPD & $55(9.6 \%)$ & $116(8.1 \%)$ & 0.254 \\
\hline Asthma & $8(1.4 \%)$ & $47(3.3 \%)$ & 0.021 \\
\hline $\begin{array}{l}\text { Bloodstream } \\
\text { infection }\end{array}$ & $3(0.5 \%)$ & $6(0.4 \%)$ & 0.742 \\
\hline Malignant tumor & $93(16.3 \%)$ & $168(11.8 \%)$ & 0.006 \\
\hline Acute heart failure & $23(4.0 \%)$ & $3 \mathrm{I}(2.2 \%)$ & 0.019 \\
\hline CURB-65 score & $1.93 \pm 0.72$ & $1.17 \pm 0.39$ & $<0.001$ \\
\hline $\begin{array}{l}\text { WBC,*10e9/l, } \\
\text { mean } \pm S D\end{array}$ & $\mid 1.81 \pm 5.54$ & $7.28 \pm 3.65$ & $<0.001$ \\
\hline NLR, mean $\pm S D$ & $14.13 \pm 11.82$ & $3.87 \pm 1.90$ & $<0.001$ \\
\hline $\begin{array}{l}\mathrm{HGB}, \mathrm{g} / \mathrm{l}, \\
\text { mean } \pm \mathrm{SD}\end{array}$ & $112.37 \pm 22.00$ & $119.79 \pm 18.40$ & $<0.001$ \\
\hline $\begin{array}{l}\mathrm{BUN}, \mathrm{mmol} / \mathrm{l} \text {, } \\
\text { mean } \pm \mathrm{SD}\end{array}$ & $9.04 \pm 5.30$ & $5.29 \pm 2.44$ & $<0.001$ \\
\hline $\begin{array}{l}\mathrm{ALT}, \mathrm{U} / \mathrm{L}, \\
\text { mean } \pm \mathrm{SD}\end{array}$ & $38.90 \pm 82.40$ & $25.79 \pm 30.08$ & 0.009 \\
\hline $\begin{array}{l}\text { AST, U/L, } \\
\text { mean } \pm S D\end{array}$ & $42.61 \pm 81.43$ & $29.63 \pm 35.21$ & $<0.001$ \\
\hline Mortality & $8 \mathrm{I}(14.2 \%)$ & $40(2.8 \%)$ & $<0.001$ \\
\hline
\end{tabular}

Abbreviations: CAP, community-acquired pneumonia; COPD, chronic obstructive pulmonary disease; WBC, white blood cell; NLR, neutrophil-to-lymphocyte ratio; HGB, hemoglobin; BUN, blood urea nitrogen; ALT, alanine transaminase; AST, aspartate aminotransferase.

This study has several limitations. First, as a singlecenter retrospective study, bias could exist during data collection. Second, treatment regimens were not included in the study, and thus the underlying factors related to this may be overlooked. To the best of our knowledge, this is the first study to identify the prognostic value of NLR*CURB-65 levels in elderly patients with CAP, and to show that it has clinical value as a marker. 


\section{Conclusion}

Compared to classic indicators such as CURB-65, NLR*CURB-65 was found to be a simpler and more accurate predictor of CAP-related in-hospital mortality in the elderly.

\section{Funding}

Guangdong Medical Research Foundation (No. A2019062).

\section{Disclosure}

The authors declare that they have no competing interests.

\section{References}

1. Aliberti S, Dela Cruz CS, Sotgiu G, Restrepo MI. Pneumonia is a neglected problem: it is now time to act. Lancet Respir Med. 2019;7(1):10-11. doi:10.1016/S2213-2600(18)30470-3

2. Roth GA, Abate D, Abate KH. GBD 2017 Causes of Death Collaborators (2018) Global, regional, and national age-sex-specific mortality for 282 causes of death in 195 countries and territories, 1980-2017: a systematic analysis for the Global Burden of Disease Study 2017. Lancet. 2018:392;1736-1788.

3. Watts N, Amann M, Ayeb-Karlsson S, et al. The Lancet Countdown on health and climate change: from 25 years of inaction to a global transformation for public health. Lancet. 2018;391(10120):581-630. doi:10.1016/S0140-6736(17)32464-9

4. Miyashita N, Yamauchi Y. Bacterial Pneumonia in Elderly Japanese Populations. Jpn Clin Med. 2018;9:1179670717751433. doi:10.1177/ 1179670717751433

5. Toledo D, Soldevila N, Torner N, et al. Factors associated with 30-day readmission after hospitalisation for community-acquired pneumonia in older patients: a cross-sectional study in seven Spanish regions. BMJ Open. 2018;8(3):e020243. doi:10.1136/bmjopen-2017-020243

6. Han X, Zhou F, Li H, et al. Effects of age, comorbidity and adherence to current antimicrobial guidelines on mortality in hospitalized elderly patients with community-acquired pneumonia. BMC Infect Dis. 2018;18(1):192. doi:10.1186/s12879-018-3098-5

7. Wang Y, Zhang S, Li L, Xie J. The usefulness of serum procalcitonin, C-reactive protein, soluble triggering receptor expressed on myeloid cells 1 and Clinical Pulmonary Infection Score for evaluation of severity and prognosis of community-acquired pneumonia in elderly patients. Arch Gerontol Geriatr. 2019;80:53-57. doi:10.1016/j. archger.2018.10.005

8. Mandell LA, Wunderink RG, Anzueto A, et al. Infectious diseases society of america; american thoracic society infectious diseases society of america/american thoracic society consensus guidelines on the management of community-acquired pneumonia in adults. Clin Infect Dis. 2007;44:S27-S72. doi:10.1086/511159

9. Lim WS, van der Eerden MM, Laing R, et al. Defining community acquired pneumonia severity on presentation to hospital: an international. Thorax. 2003;58(5):377-382.

10. Trinh HT, Hoang PH, Cardona-Morrell M, et al. Antibiotic therapy for inpatients with community-acquired pneumonia in a developing country.[J]. Pharmacoepidemiol Drug Saf. 2015;24(2):129-136. doi:10.1002/pds.3614
11. Chong CP, Street PR. Pneumonia in the elderly: a review of severity assessment, prognosis, mortality, prevention, and treatment. South Med J. 2008;101(11):1134-1140. doi:10.1097/SMJ.0b013e31818247f1

12. Komiya K, Rubin BK, Kadota JI, et al. Prognostic implications of aspiration pneumonia in patients with community acquired pneumonia: a systematic review with meta-analysis[J]. Rep. 2016;6(1):38097.

13. Chen L, Zhou F, Li H, et al. Disease characteristics and management of hospitalised adolescents and adults with community-acquired pneumonia in China: a retrospective multicentre survey[J]. BMJ Open. 2018;8(2):e018709. doi:10.1136/bmjopen-2017-018709

14. Sacks D, Baxter B, Campbell BCV, From the American Association of Neurological Surgeons (AANS), American Society of Neuroradiology (ASNR), Cardiovascular and Interventional Radiology Society of Europe (CIRSE). Multisociety consensus quality improvement revised consensus statement for endovascular therapy of acute ischemic stroke. Int J Stroke. 2018;13(6):612-632. doi: $10.1177 / 1747493018778713$

15. Aston SJ, Ho A, Jary H, et al. Etiology and risk factors for mortality in an adult community-acquired pneumonia cohort in malawi. Am J Respir Crit Care Med. 2019;200(3):359-369. doi:10.1164/rccm.201807-1333OC

16. Arias-Fernández L, Gil-Prieto R, Gil-de-miguel Á. Incidence, mortality, and lethality of hospitalizations for community-acquired pneumonia with comorbid cardiovascular disease in Spain (1997-2015). BMC Infect Dis. 2020;20(1):477. doi:10.1186/s12879-020-05208-y

17. Pessoa E, Bárbara C, Viegas L, Costa A, Rosa M, Nogueira P. Factors associated with in-hospital mortality from community-acquired pneumonia in Portugal: 2000-2014. BMC Pulm Med. 2020;20(1):18. doi:10.1186/s12890-019-1045-x

18. Rodrigues AM, Gregório MJ, Sousa RD, et al. Challenges of ageing in Portugal: data from the EpiDoC cohort. Acta Medica Port. 2018;31 (2):80-93. doi:10.20344/amp.9817

19. Schuetz P, Koller M, Christ-Crain M, et al. Predicting mortality with pneumonia severity scores: importance of model recalibration to local settings. Epidemiol Infect. 2008;136(12):1628-1637. doi:10.1017/ S0950268808000435

20. Braun E, Kheir J, Mashiach T, Naffaa M, Azzam ZS. Is elevated red cell distribution width a prognostic predictor in adult patients with community acquired pneumonia? BMC Infect Dis. 2014;14(1):129. doi:10.1186/1471-2334-14-129

21. Shi T, Chen C, Huang L, et al. Risk factors for mortality from severe community-acquired pneumonia in hospitalized children transferred to the pediatric intensive care unit. Pediatr Neonatol. 2020;S1875S9572(20):30098-X. doi:10.1016/j.pedneo.2020.06.005

22. Reade MC, Weissfeld L, Angus DC, Kellum JA, Milbrandt EB. The prevalence of anemia and its association with 90-day mortality in hospitalized community-acquired pneumonia. BMC Pulm Med. 2010;10(1):15. doi:10.1186/1471-2466-10-15

23. Fink MP. Pathophysiology of intensive care unit-acquired anemia. Crit Care. 2004;8(Suppl 2):S9-10. doi:10.1186/cc2410

24. Huang Y, Liu A, Liang L, et al. Diagnostic value of blood parameters for community-acquired pneumonia. Int Immunopharmacol. 2018;64:10-15. doi:10.1016/j.intimp.2018.08.022

25. Kartal O, Kartal AT. Value of neutrophil to lymphocyte and platelet to lymphocyte ratios in pneumonia. Bratisl Lek Listy. 2017;118 (9):513-516. doi:10.4149/BLL_2017_099

26. Zhang HF, Ge YL, Wang HY, et al. Neutrophil-to-lymphocyte ratio improves the accuracy and sensitivity of pneumonia severity index in predicting 30-day mortality of CAP patients. Clin Lab. 2019;65:10. doi:10.7754/Clin.Lab.2019.190226 


\section{Publish your work in this journal}

The International Journal of General Medicine is an international, peer-reviewed open-access journal that focuses on general and internal medicine, pathogenesis, epidemiology, diagnosis, monitoring and treatment protocols. The journal is characterized by the rapid reporting of reviews, original research and clinical studies across all disease areas. The manuscript management system is completely online and includes a very quick and fair peer-review system, which is all easy to use. Visit http://www.dovepress.com/ testimonials.php to read real quotes from published authors.

Submit your manuscript here: https://www.dovepress.com/international-journal-of-general-medicine-journal 